\title{
Anaemia in pregnancy in a setting of high HIV prevalence rates
}

\author{
Kay Tunkyia and Jagidesa Moodleya* \\ ${ }^{a}$ Department of Obstetrics and Gynaecology, University of KwaZulu-Natal, Durban, South Africa \\ *Corresponding author, email:jmog@ukzn.ac.za
}

Background: Although there is much literature on anaemia in pregnancy, there are limited data on anaemia specific to HIV in pregnancy. The aim of this study was to determine the prevalence of anaemia among HIV-infected antenatal attendees at their first visit.

Methods: This was a secondary analysis of 2000 antenatal attendees enrolled into a study on anaemia in pregnancy and was carried out at a regional hospital from 2012-2014. Demographic and clinical data including anaemia, perinatal and maternal outcomes of HIV infected women were analysed.

Results: Of the 2000 recruited, 854 (42.7\%) were anaemic, 943 (47.2\%) were infected with HIV, and 609 (64.6\%) HIV-infected women had anaemia.

There was a significant difference in the prevalence of anaemia in HIV-infected patients on antiretroviral (ARV) treatment compared to untreated patients $(41.4 \%$ vs $92.1 \% ; p<0.0001)$. Mild grades of anaemia were common in HIV-infected patients on ARVs, while moderate to severe grades were most common in patients who were not on ARVs. Besides birthweight and hypertensive disorders of pregnancy, there was no significant difference in neonatal and maternal outcomes irrespective of duration of ARV treatment.

Conclusions: There was a high prevalence of anaemia among HIV-infected, untreated pregnant women. Assessment of anaemia at the first antenatal visit is, therefore, essential.

Keywords: anaemia, HIV, pregnancy

\section{Introduction}

Anaemia and HIV infections are important public health issues affecting millions of people globally., ${ }^{1,2}$ Pregnant women in particular are vulnerable to both anaemia and HIV infections. ${ }^{1,2}$ Recently, Oladeinde et al. reported that the prevalence of HIV and anaemia in a rural community in Nigeria was $11.7 \%$ and $49.3 \%$, respectively. ${ }^{3}$ Similar reports originate from other west and east African countries..$^{4-6}$ Okeudo et al. also showed that HIV infection increased the frequency of anaemia in a Nigerian population. ${ }^{4}$ South Africa (SA) has higher rates of HIV infection than that reported from Nigeria, while rates of anaemia are similar. ${ }^{7-10}$ In a South African rural province, the overall prevalence of anaemia $(<10 \mathrm{~g} / \mathrm{dl})$ was $19.7 \%,{ }^{8}$ while that in an urban setting serving a low socio-economic population was $42.7 \%(<11 \mathrm{~g} / \mathrm{dl}){ }^{7}$

The prevalence of HIV infection in antenatal attendees in SA is approximately $30 \% .^{10}$ Reports from other countries in Africa including SA show increased rates of anaemia in HIV-infected women, and it has been suggested that the increased prevalence may be explained by the fact that this viral infection is associated with low serum folate, vitamin B12 and ferritin levels in pregnancy. ${ }^{4,11,12}$ In addition, the use of anti-retroviral agents such as zidovudine either for the prevention of mother to child transmission or treatment of HIV have also been implicated in the development of anaemia. ${ }^{12}$ Furthermore, anaemia associated with HIV and AIDS may arise from destruction or inhibition of haematopoietic cells and it is reported to be a marker of disease progression. ${ }^{5}$ Thus, HIV is independently reported to cause anaemia. ${ }^{5,13}$ A recent retrospective study by Nandlal et al. in pregnant women with advanced HIV and AIDS showed that $64.2 \%$ had anaemia. ${ }^{9}$ There is, however, limited data on anaemia in HIV pregnant women with high CD4 cell counts in South Africa.

\section{Methods}

Following institutional regulatory permissions (Biomedical Research Ethics Committee of the University of KwaZulu-Natal: BE 306/12) venous blood samples for complete blood counts were obtained from 2000 consenting antenatal attendees at their first antenatal visit. All women except those who were infected with HIV, or were not on any other medications at the time of the study, were entered into the study. The standard practice at the study site was to offer all women a HIV screening blood test and a complete blood count. In addition, all women had syphilis and rhesus testing. Those who tested HIV-positive and those known to be HIV infected on treatment had CD4 cell counts performed. Relevant demographic and clinical information were entered in a structured data sheet.

Anaemia in pregnancy was defined according to the WHO classification of a haemoglobin $(\mathrm{Hb})$ concentration of $<11 \mathrm{~g} / \mathrm{d} .^{2}$ All women received prophylactic iron therapy (oral ferrous sulphate, $200 \mathrm{mgs}$ daily) and folic acid, $5 \mathrm{mgs}$ daily. The haemoglobin $(\mathrm{Hb})$ concentration levels were arbitrarily divided into the following groups: (i) > $11 \mathrm{~g} / \mathrm{dl}$; (ii) between 10-10.9 g/dl; (iii) between 7-9.9 $\mathrm{g} / \mathrm{dl}$; and, (iv) $<7 \mathrm{~g} / \mathrm{dl}$ and below, for the purposes of the study. The incidence of smoking in the population studied was low (approximately 3\% according to hospital statistics) and the study site was a regional hospital in an urban setting at sea level serving a low socio-economic population.

\section{Statistical Analysis}

Data was entered into a computer database using Microsoft Excel software and was analysed using SPSS (version 23). Continuous variables were described as mean and standard deviation, whereas categorical variables were expressed by frequency and percentage. A $p$-value of $<0.05$ was judged to be statistically significant. 


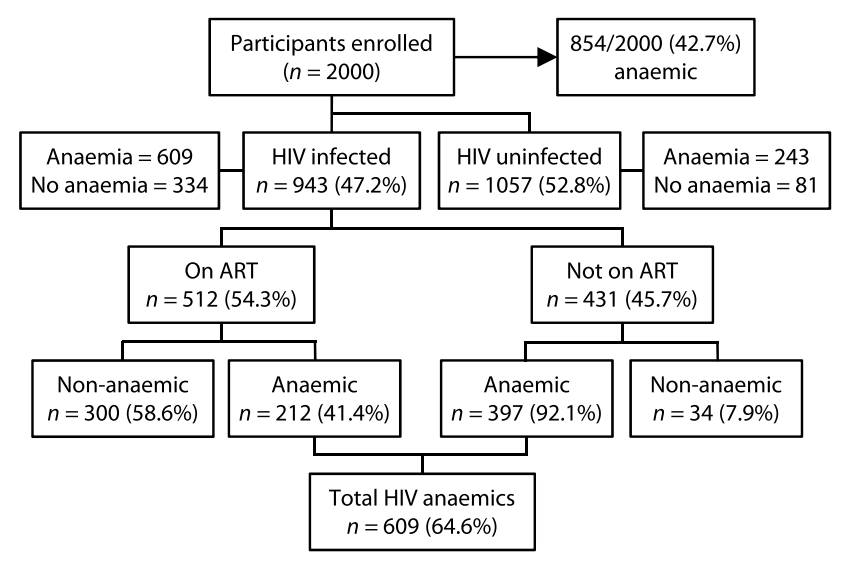

Figure 1: All HIV-infected women with anaemia. $A R T=$ antiretroviral therapy.

Table 1: Demographic and obstetric data of HIV Infected anaemic participants at booking

\begin{tabular}{|c|c|c|c|c|}
\hline Variable & $\begin{array}{c}\text { Total } \\
(n=609)\end{array}$ & $\begin{array}{c}\text { HIV infected } \\
\text { on ARVs } \\
(n=212)\end{array}$ & $\begin{array}{l}\text { HIV infected } \\
\text { ARVs naive } \\
(n=397)\end{array}$ & $p$-value \\
\hline $\begin{array}{l}\text { Mean age } \\
\text { years (range) }\end{array}$ & $25.3(17-40)$ & $27.5(24-40)$ & $24.5(17-31)$ & 0.01 \\
\hline \multicolumn{5}{|c|}{ Age groups (years) } \\
\hline$\leq 19$ & $84(13.8 \%)$ & $21(9.9 \%)$ & 63 (15.9\%) & 0.02 \\
\hline $20-24$ & 249 (40.9\%) & $89(41.9 \%)$ & $160(40.3 \%)$ & 0.7 \\
\hline $25-30$ & $154(25.3 \%)$ & $46(21.7 \%)$ & $108(27.2 \%)$ & 0.1 \\
\hline $31-34$ & 81 (13.3\%) & 42 (19.8\%) & $39(9.8 \%)$ & 0.0005 \\
\hline$\geq 35$ & $41(6.7 \%)$ & $14(6.6 \%)$ & $27(6.8 \%)$ & 0.9 \\
\hline Mean parity & $2.1 \pm 1.0(1-4)$ & $\begin{array}{c}2.1 \pm 1 \\
(1-4)\end{array}$ & $\begin{array}{c}2.2 \pm 1.1 \\
(1-3)\end{array}$ & 0.4 \\
\hline \multicolumn{5}{|c|}{ Mean gestation } \\
\hline $\begin{array}{l}\text { Age at book- } \\
\text { ing (weeks) }\end{array}$ & $\begin{array}{c}24.2 \pm 3.1 \\
(17-34)\end{array}$ & $\begin{array}{c}26.4 \pm 2.1 \\
(24-34)\end{array}$ & $\begin{array}{c}24.2 \pm 1.1 \\
(17-32)\end{array}$ & 0.2 \\
\hline
\end{tabular}

ARV-antiretroviral drugs.

\section{Results}

Two thousand antenatal attendees were enrolled in the initial study. The mean (SD) age was $27.6 \pm 7.6$ years; the mean parity was $2.0 \pm 1.1$ and the mean (SD) gestational age at first visit was $24 \pm 2.24$ weeks. Eight hundred and fifty-four of the 2000 antenatal participants were anaemic with a prevalence of $42.7 \%$ at entry into the study.

Figure 1 shows that of the 2000 women enrolled, 943 (47.2\%) patients were HIV infected and of these 609 were anaemic giving a prevalence rate of $64.6 \%$. Five hundred and twelve of the 943 HIV infected patients (54.3\%) were on antiretroviral (ARV) agents of which $212(41.4 \%)$ patients were anaemic. Four hundred and thirty-one (45.7\%) were ARV-naive, of which 397 (92.1\%) were anaemic. There was significant difference in the incidence of anaemia in HIV infected patients on ARV treatment compared to HIV-infected ARV-naive patients ( $41.4 \%$ vs $92.1 \% ; p<0.0001)$.

Table 1 shows the demographic data of the 609 HIV-infected anaemic patients. The mean (SD) age was $25.3(17-40)$ years compared to $27.5(24-40)$ years in participants on ARV treatment and $24.5(17-31)$ years in ARV-naive participants. The mean (SD) parity and gestational age of the HIV-infected participants at first
Table 2: Stratified Haemoglobin levels of HIV-infected patients with anaemia at booking

\begin{tabular}{|l|c|c|c|c|}
$\begin{array}{l}\text { Grades of } \\
\text { anaemia }\end{array}$ & $\begin{array}{c}\text { Hb levels } \\
(\mathbf{g} / \mathbf{d l})\end{array}$ & $\begin{array}{c}\text { HIV- } \\
\text { infected } \\
\text { on ARVs } \\
(\boldsymbol{n}=\mathbf{2 1 2})\end{array}$ & $\begin{array}{c}\text { HIV- } \\
\text { infected } \\
\text { ARV-naive } \\
(\boldsymbol{n}=397)\end{array}$ & $p$-value \\
\hline Mild & $10.0-10.9$ & $123(58 \%)$ & $92(24.4 \%)$ & 0.0001 \\
\hline Moderate & $7-9.9$ & $89(42 \%)$ & $295(74.3 \%)$ & 0.0001 \\
\hline Severe & $<7.0$ & $0(0 \%)$ & $5(12.6 \%)$ & 0.0001 \\
\hline
\end{tabular}

visit was $2.1 \pm 1.0$ and $24 \pm 3.1$ weeks, respectively. The highest prevalence of HIV infection (40.9\%) was in the age group 20-24 years.

Five hundred and twelve (56.3\%) participants were on HIV treatment for 1 to 3 years prior to pregnancy, of which 212 (41.4\%) were anaemic.

Four hundred and thirty-one HIV-infected women were ARVnaive, of which 397 (43.7\%) were anaemic and received HIV treatment at diagnosis, namely with zidovudine (ZDV) prophylaxis or triple ARV. ARV therapy was started at a mean gestational age of $26.2 \pm 3.1$ weeks.

Table 2 shows the grades of anaemia. The mild type was more common in HIV-infected patients on treatment, while moderate to severe anaemia was more common in ARV-naive patients.

In HIV-infected women, the main types of anaemia were hypochromic microcytic ( $n=7 ; 1.1 \%)$, normochromic normocytic ( $n=424 ; 69.6 \%)$, hypochromic normocytic $(n=108 ; 17.7 \%)$ and normochromic microcytic $(n=70 ; 11.5 \%)$ (Table 3$)$. There was no

Table 3: Types of anaemia in HIV-infected participants at booking

\begin{tabular}{|l|c|c|c|}
\hline $\begin{array}{l}\text { Types of } \\
\text { anaemia }\end{array}$ & $\begin{array}{c}\text { HIV infected on } \\
\text { ARVs }(\boldsymbol{n}=212)\end{array}$ & $\begin{array}{c}\text { HIV infected } \\
\text { ARV-naïve } \\
(\boldsymbol{n}=397)\end{array}$ & $p$-value \\
\hline $\begin{array}{l}\text { Hypochromic } \\
\text { microcytic }\end{array}$ & $1(0.5 \%)$ & $6(1.5 \%)$ & 0.2 \\
\hline $\begin{array}{l}\text { Normochromic } \\
\text { normocytic }\end{array}$ & $147(69.3 \%)$ & $277(69.8 \%)$ & 0.8 \\
\hline $\begin{array}{l}\text { Hypochromic } \\
\text { normocytic }\end{array}$ & $44(20.8 \%)$ & $64(16.8 \%)$ & 0.2 \\
\hline $\begin{array}{l}\text { Normochromic } \\
\text { microcytic }\end{array}$ & $20(9.4 \%)$ & $50(12.6 \%)$ & 0.2 \\
\hline
\end{tabular}

Table 4: Maternal and neonatal morbidity and mortality of the HIVinfected anaemic participants $(n=609)$ based on duration of HIV treatment

\begin{tabular}{|l|c|c|c|}
\hline Variable & $\begin{array}{c}\text { HIV positive on } \\
\text { ARVS 1-3 years } \\
(\boldsymbol{n}=212)\end{array}$ & $\begin{array}{c}\text { HIV positive on } \\
\text { ARVs <1 year } \\
(\boldsymbol{n}=397)\end{array}$ & $p$-value \\
\hline Preterm labour & $24(11.3 \%)$ & $43(10.8 \%)$ & 0.8 \\
\hline Stillbirths & $5(2.4 \%)$ & $11(2.8 \%)$ & 0.2 \\
\hline Birthweight $(\mathrm{kg})$ & $3.2 \pm 0.8$ & $2.87 \pm 0.4$ & $0.0001^{*}$ \\
\hline Neonatal mortality & $1(0.5 \%)$ & $4(1 \%)$ & 0.5 \\
\hline $\begin{array}{l}\text { Hypertensive } \\
\text { disorders }\end{array}$ & $11(5.2 \%)$ & $4(1 \%)$ & $0.0001^{*}$ \\
\hline Abruptio placentae & $2(0.9 \%)$ & $7(1.8 \%)$ & 0.3 \\
\hline
\end{tabular}

${ }^{*} p<0.0001$. 
difference in the type of anaemia between patients who received ARV treatment compared to ARV-naive patients. Normocytic normochromic anaemia was the most common. Normochromic microcytic anaemia was least common.

Table 4 lists the neonatal and maternal morbidity and mortality of HIV-infected patients based on the duration of HIV treatment. Except for neonatal bodyweight and hypertensive disorders of pregnancy, there was no significant difference in neonatal and maternal morbidity between patients who received ARV treatment for 1-3 years compared to those who had treatment for $<1 \mathrm{yr}$.

\section{Discussion}

The major findings in this study are an antenatal prevalence rate of HIV of $47.2 \%$ and a high prevalence of anaemia at entry of $42.7 \%$ of the study participants to this study. ${ }^{7}$ The high prevalence rate in the study site may be a reflection of an increase in the awareness and acceptance of HIV screening. Similar prevalence rates of anaemia have been reported from other low and middle income countries, such as Nigeria where Oladeinde et al. and Okeudo et al. reported that the prevalence rates among pregnant women were $49.3 \%$ and $59.9 \%$ respectively.,4 Our population was a low socio-economic urban community and probably similar to that of the Nigerian studies, except malarial infection rates are low in the South African (SA) province in which the study site was situated. The Saving Mother's Report 2011-2013 also found that $42.4 \%$ of maternal deaths occurred in women who were anaemic $(<10 \mathrm{~g} / \mathrm{dl})$. In addition, the 2014 annual Saving Mothers Report published by the SA Department of Health indicated that of all women who died from non-pregnancy related infections, mainly HIV/AIDS, $58.2 \%$ were anaemic. ${ }^{14}$

The prevalence of anaemia in HIV-infected women in our study was $64.6 \%$. This is in keeping with the study of Nandlal et al. who did a retrospective cohort data analysis of anaemia in a similar population group. ${ }^{9}$ These authors found a prevalence rate of $64.5 \%$ but most of their study participants had advanced HIV (CD4 $<200$ cells $/ \mathrm{mm}^{3}$; WHO grades 3 and 4 ) while on antiretroviral therapy. None of our study population had co-morbid diseases, such as tuberculosis, and all were healthy antenatal attendees with no previous history of admissions to a health facility during the current pregnancy. Furthermore, all the participants in our study had lesser severity of HIV infection, with a median CD4 cell count of 486 cells $/ \mathrm{mm}^{3}$ (range: $422-546$ cells $/ \mathrm{mm}^{3}$ ).

The prevalence of anaemia in our study of those patients who tested HIV-seropositive for the first time was $34.5 \%$ and may be a more accurate reflection of their $\mathrm{Hb}$ concentration levels. The women who were seropositive at first testing were not on any HIV antiretroviral drugs and were not on multivitamin, iron or folic acid prophylactic supplementation. Antiretroviral drugs (ARVs), especially zidovudine, has been reported to cause anaemia, ${ }^{5,6,13}$ which may be related to the duration of the use of these drugs. In a study from Thailand, comparing maternal anaemia between HIV-infected pregnant women receiving zidovudine-based and zidovudine-free highly active antiretroviral therapy (HAART); the outcome showed that both zidovudinebased and zidovudine-free HAART exposure was associated with substantial risk of maternal anaemia during pregnancy two to three months after exposure. ${ }^{15,16}$ Similarly, Sartorius et al. conducted a randomised trial in three African countries, including $\mathrm{SA}$, showed that severe anaemia occurred at a similar rate in women receiving a zidovudine-containing ARV regimen with a short or long duration. ${ }^{5}$ Moreover, it appeared that women with severe anaemia reduced their $\mathrm{Hb}$ concentrations after a few months of treatment with ARV therapy. Overall, we found that $41 \%$ of HIV-positive pregnant women with anaemia were on ARV treatment, compared to $92 \%$ of HIV-infected pregnant women with anaemia who were not on ARV treatment. Thus, it seems that ARV therapy may have a positive impact on $\mathrm{Hb}$ levels. ${ }^{5,12}$ However persistent low $\mathrm{Hb}$ levels may signify deterioration in the disease process. ${ }^{15}$ Odhiambo et al. had similar findings in a mother-to-child ARV prevention study in which they found resolution amongst 550 women who continued with ARV therapy for up for 2 years from the time of child birth. ${ }^{12}$ Berhane et al. also showed similar results with at least 6 months of ARV usage. ${ }^{17}$ Thus, it seems that ARV therapy certainly increases the resolution of anemia and this might be due to the effects of ARVs on inflammation and chronic infection. However, it can be argued that women receiving $A R V$ s also receive iron, folic acid, multivitamin and other nutritional supplements, which may have an overall positive impact on health.

Most of the types of anaemia in our study were normocytic normochromic in type suggesting that iron deficiency is not a major factor in the aetiology of the anaemia. Similar findings were reported from Uganda who evaluated serum ferritin levels and transferritin receptor levels to establish the contribution of iron and common infections in pregnant women. Baingana et al. indicate that chronic infections and inflammation have a greater role in the aetiology of anaemia. ${ }^{6}$

Previous studies have shown that anaemia had an impact on neonatal and maternal morbidity and mortality. Tunkyi et al. reported that anaemia is an important obstetric complication which affects both mother and child. ' In our study, Table 4 shows the neonatal and maternal morbidity and mortality outcomes in HIV-infected women; and, except for birthweight and hypertensive disorders of pregnancy, there were no significant differences in perinatal and maternal morbidity between patients who received and did not receive HAART.

There was a high incidence of anaemia among HIV-infected pregnant women at entry. There was a significant difference in the incidence of anaemia in HIV-infected patients on ARV treatment compared to HIV-infected ARV-naive pregnant women at booking. There was no difference in perinatal and maternal morbidity between patients who received antiretroviral treatment irrespective of duration of treatment.

In conclusion, anaemia is a common finding in pregnant women diagnosed with HIV with high perinatal and maternal morbidity rates. Assessment of anaemia at the first antenatal visit is therefore essential as it affords one the opportunity to establish the exact cause of low $\mathrm{Hb}$ concentration levels, and institute interventions to prevent complications. It must be recognised, however, that anaemia is not a diagnosis and must prompt detailed investigations for the underlying cause in particular chronic infections.

Conflict of interests - The authors have neither conflict of interests nor financial declarations to declare.

\section{References}

1. Finkelstein $\mathrm{J}$, Mehta $\mathrm{S}$, Duggan $\mathrm{CP}$, et al. Predictors of anaemia and iron deficiency in HIV-infected pregnant women in Tanzania: a potential role for vitamin D and parasitic infections. Public Health Nutr. 2012;15(5): 928-37. doi:10.1017/S136898002369.

2. World Health Organization. Micronutrient deficiencies. Iron deficiency anaemia; 2008 [cited 2016 March]. Available from: www:who.int.who. int/nutrition/topics/ida/en/index.html. 
3. Oladeinde $\mathrm{BH}$, Phil RM, Olley $\mathrm{M}$, et al. Prevalence of HIV and anaemia among pregnant women. North Am J Med Sci. 2011;3:548-51. doi:10.4297/najms.2011.3548.

4. Okeudo C, Ezem BU, Ojiyi EC, et al. Prevalence of anaemia among human immunofdeficiency virus (HIV) positive pregnant women at booking in Orlu, in South-Eastern Nigeria. Afr Med J. 2014;5(1):45-9.

5. Sartorius BKD, Chersich MF, Mwaura M, et al., The Kesho Bora Study Group. Maternal anaemia and duration of zidovudine in antiretroviral regimens for preventing mother-to-child transmission: a randomized trial in three African countries. BMC Infectious Diseases 2013;13:522. https://doi.org/10.1186/1471-2334-13-522

6. Baingana RK, Enyaru JK, Tjalsma $\mathrm{H}$, et al.The aetiology of anaemia during pregnancy: a study to evaluate the contribution of iron deficiency and common infections in pregnant Ugandan women. Pub Hlth Nutr. 2015;18(8):1423-35. https://doi.org/10.1017/S1368980014001888

7. Tunkyi K, Moodley J. Prevalence of anaemia in pregnancy in a regional health facility in South Africa. S Afr Med J. 2015;106(1):101-4. https://doi.org/10.7196/SAMJ.2016.v106i1.9860

8. van Bogaert L-G. Anaemia and pregnancy outcomes in a South African rural population. J Obstet Gynaecol. 2006;26(7):617-29. https://doi.org/10.1080/01443610600902901

9. Nandlal V, Moodley D, Grobler A, et al. Anaemia in pregnancy is associated with advanced HIV disease. PLoS ONE 2014;9(9): e106103. doi:10.1371/journal.pone.0106103.

10. The 2012 National antenatal sentinel HIV and herpes simplex type 2 . Prevalence survey in South Africa. Pretoria: National Department of Health; 2012. p. 2012.

11. Adesina $O$, Oladokun $A$, Akinyemi $O$, et al. Risk of anaemia in HIV positive pregnant women in Ibadan, South West Nigeria. Afr J Med Med Sci. 2011;40(1):67-73.
12. Odhiambo C, Zeh C, Angira F, et al. Anaemia in HIV-infected pregnant women receiving triple antiretroviral combination therapy for prevention of mother-to-child transmission: a secondary analysis of the Kisumu breastfeeding study (KiBS). Trop Med Int HIth. 2016;21(3): 373-84. https://doi.org/10.1111/tmi.2016.21.issue-3

13. Takuva S, Maskew M, Brennan AT, et al. Anemia among HIV-infected patients initiating antiretroviral therapy in South Africa: improvement in hemoglobin regardless of degree of immunosuppression and the initiating ART regimen. J Trop Med. 2013; 162950. Published online 2013 Aug 27. doi:10.1155/2013/162950.

14. Annual saving mothers report-2014 and HIV comprehensive chapter. Pretoria: National Department of Health; 2016.

15. Lertcheewakarn P, Tongprasert FA. Comparison of maternal anemia between HIV infected pregnant women receiving zidovudine-based and zidovudine-free highly active antiretroviral therapy (HAART). J Med Assoc Thai. 2014; 197(4):1-6.

16. Yapan P, Chalermchockcharoenkit A. Prevalence, associated factors and pregnancy outcomes of anemia during intrapartum period in HIV-Infected pregnant women. Thai J Obstets Gynaecol. 2014;22: 143-9.

17. Berhane $\mathrm{K}$, Karim $\mathrm{R}$, Cohen $\mathrm{MH}$, et al. Impact of highly active antiretroviral therapy on anaemia and relationship between anaemia and survival in a large cohort of HIV-infected women: Women's Interagency HIV Study. J Acquir Defic Syndr. 2004;37(2):1245-52. https://doi.org/10.1097/01.qai.0000134759.01684.27

Received: 27-09-2016 Accepted: 12-06-2017 